\begin{tabular}{|c|c|}
\hline Title & Visible and near-infrared reflectance spectroscopy for rice taste evaluation \\
\hline Author(s) & Kawamura, S.; Natsuga, M.; Itoh, K. \\
\hline Citation & $\begin{array}{l}\text { Transactions of the A SA E, 40(6), 1755-1759 } \\
\text { https://doi.org } / 10.13031 / 2013.21408\end{array}$ \\
\hline Issue Date & 1997 \\
\hline Doc URL & http:/hdl.handle.net/2115//1224 \\
\hline Rights & (19197 A merican Society of A gricultural Engineers 0001-2351/97/4006-1755 \\
\hline Type & article \\
\hline File Information & Ka1997-1 NIR for Rice Taste Evaluation Published A SA E.pdf \\
\hline
\end{tabular}

Instructions for use 


\title{
VISIBLE AND NEAR-INFRARED REFLECTANCE SPECTROSCOPY FOR RICE TASTE EVALUATION
}

\author{
S. Kawamura, M. Natsuga, K. Itoh
}

\begin{abstract}
Visible and near-infrared (VIS/NIR) spectroscopy calibration models for rice taste evaluation were developed using 61 short-grain rice samples. The best performance calibration model was obtained from original spectra of whole grain milled rice using multiple linear regression $(M L R)$ analysis. The correlation coefficient $(r)$ and the standard error of prediction (SEP) of the validation set was 0.62 and 0.27 , respectively. However, this was not adequate to justify replacing sensory tests with the calibration model for evaluating rice taste. The results indicated that VIS/NIR technology could be used for classifying rice samples into qualitative groups, such as poor taste, better taste and the best taste.
\end{abstract}

Keywords. Spectroscopy, VIS/NIR, Rice, Taste, Sensory test, Physicochemical properties.

$\mathrm{T}$ he most important quality of any food is taste, especially for consumers. A group of people trained in sensory perception (sometimes called a "sensory panel") is used to evaluate taste of rice.

Physicochemical properties of rice can be measured using many different methods. For example, near-infrared (NIR) spectroscopy has been used to measure the chemical composition of grain, including such constituents as moisture, protein and amylose, with high accuracy (Iwamoto et al., 1986; Natsuga et al., 1993; Villareal et al., 1994; Delwiche et al., 1995; Delwiche et al., 1996).

There are commercial NIR rice-taste meters in use today. However, they are not accurate enough to replace sensory tests for evaluating rice taste (Kawamura et al., 1996).

Even though physicochemical properties of rice can be measured, it has been difficult to develop an instrument that would substitute for the sensory panel.

There were two objectives in this study. They were to:

- Determine the properties that affect rice taste.

- Develop a calibration model for evaluating the taste of rice using visible and near-infrared (VIS/NIR) spectroscopy, and to validate the accuracy of the model.

\section{Materials AND METHODS \\ Rice SAMPLES}

Sixty-one short-grain brown rice samples (at least $5 \mathrm{~kg}$ per sample) were selected from commercial releases all over Japan for this study. The samples were chosen from 29 varieties of Japanese non-waxy rice.

\footnotetext{
Article has been reviewed and approved for publication by the Information \& Electrical Technologies Div. of ASAE. Presented as ASAE Paper No. 96-3032.

The authors are Shuso Kawamura, ASAE Member Engineer, Associate Professor, Motoyasu Natsuga, ASAE Member Engineer, Researcher, and Kazuhiko Itoh, Professor, Dept. of Agricultural Engineering, Hokkaido University, Sapporo, Japan. Corresponding author: Shuso Kawamura, Agricultural Process Engineering Division, Agricultural Engineering Dept., Hokkaido University, Sapporo, 060 Japan; e-mail<shuso@agm.hokudai.ac.jp>.
}

Figure 1 shows the sample processing, experimental, and data analyzing procedures. The brown rice samples (at least $3 \mathrm{~kg}$ per sample) were milled with a commercial friction mill (model MCM-250, Satake Engineering, Tokyo, Japan). The milling yield of each milled rice sample was controlled at $90.5 \%( \pm 0.1 \%)$.

\section{Physicochemical Properties}

Physicochemical properties were determined for the milled rice samples (fig. 1) as follows.

Moisture content was determined by the JSAM (Japanese Society of Agricultural Machinery) standard method; about $10 \mathrm{~g}$ of whole grain rice sample was placed in a forced air oven at $135^{\circ} \mathrm{C}$ for $24 \mathrm{~h}$ and moisture was computed on a wet basis. Amylose content (apparent amylose content) measurements were performed with an autoanalyzer, following the protocol of Williams et al. (1958) with modifications by Inatsu (1988). The protein content was

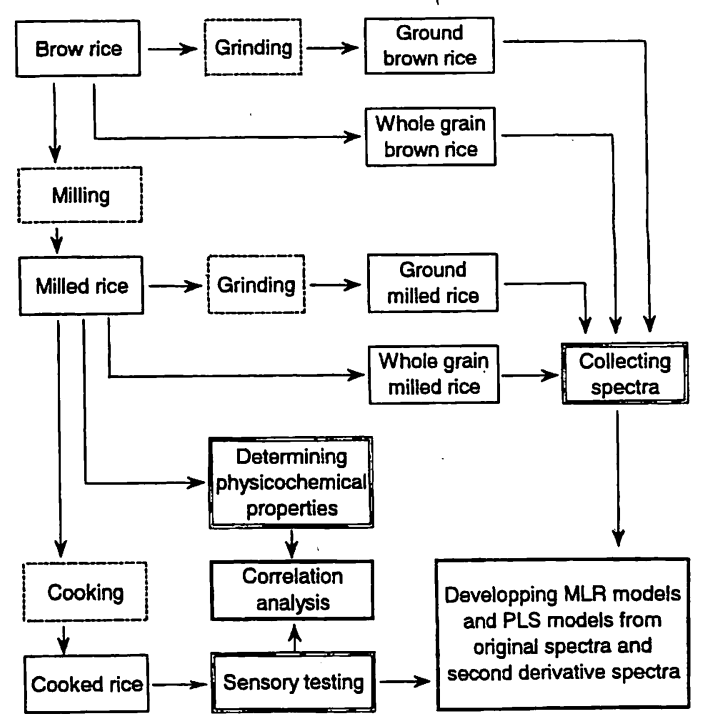

Figure 1-Sample processing, experimental, and data analyzing procedures. 
measured on an NIR spectrometer (model Instalab-600, DICKY-john, Auburn, Ill.), and calculated on a dry basis. Free fat acidity value was determined by the AACC (American Association of Cereal Chemists) rapid method.

Whiteness, saturation, and translucency were measured on a whiteness meter (model C-100, Kett Electric Laboratory, Tokyo, Japan), a color difference meter (model CR-200b, Minolta Camera, Osaka, Japan) and a rice meter (model QS-101D, Riken Instrument, Tokyo, Japan), respectively.

The texturogram A1 was defined by the first peak area of the texture profile measured on a texturometer (Zenken, Tokyo, Japan). This calculated value was usually associated with the hardness of cooked rice. Amylogram maximum viscosity (MV) was defined by the magnitude of the curve recorded on an amylograph (Brabender, Duisburg, Germany). It represented the maximum viscosity of milled rice flour paste during the heating process. Rapid visco analyzer (RVA) peak was defined by the magnitude of the curve recorded on a rapid visco analyzer (Newport Scientific, Warriewood, NSW, Australia). It was similar to the amylogram MV.

\section{SENSORY TEST}

Fourteen sensory tests were carried out for this study, according to the Japanese official rice taste testing method standardized by the Japan Food Agency. The test was conducted once per day and always started at 3:00 P.M.

Cooking rice was accomplished with eight electric rice cookers (model RC-187F, Toshiba, Tokyo, Japan) for one test. The cooking procedures were the same for all samples; washing $1 \mathrm{~kg}$ milled rice for $3 \mathrm{~min}$, rinsing it three times, adding up to $1.3 \mathrm{~kg}$ of water (the total weight of milled rice and water was $2.3 \mathrm{~kg}$ ), soaking it for $2 \mathrm{~h}$, heating it for half an hour, and aging it for one-half hour before the sensory test.

Panelists were selected with gender and age balance, and trained for the test in advance. They were collected in a lecture room and divided into six panel groups (fig. 2). The mean, maximum and minimum numbers of panel members of 14 sensory tests were 41,47 , and 34 , respectively. The lecture room was equipped with neutral color fluorescent lights and the natural sunlight came in the room through

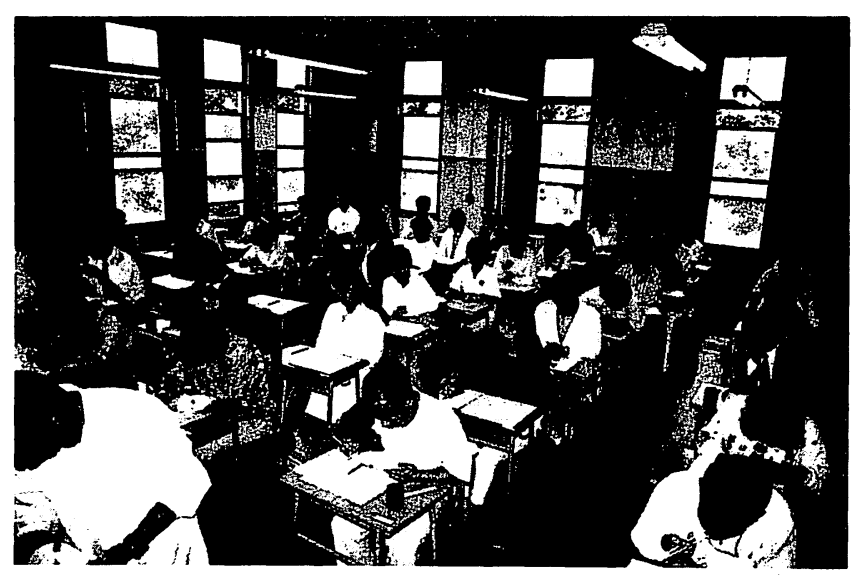

Figure 2-Panelists divided into six panel groups evaluating rice taste.

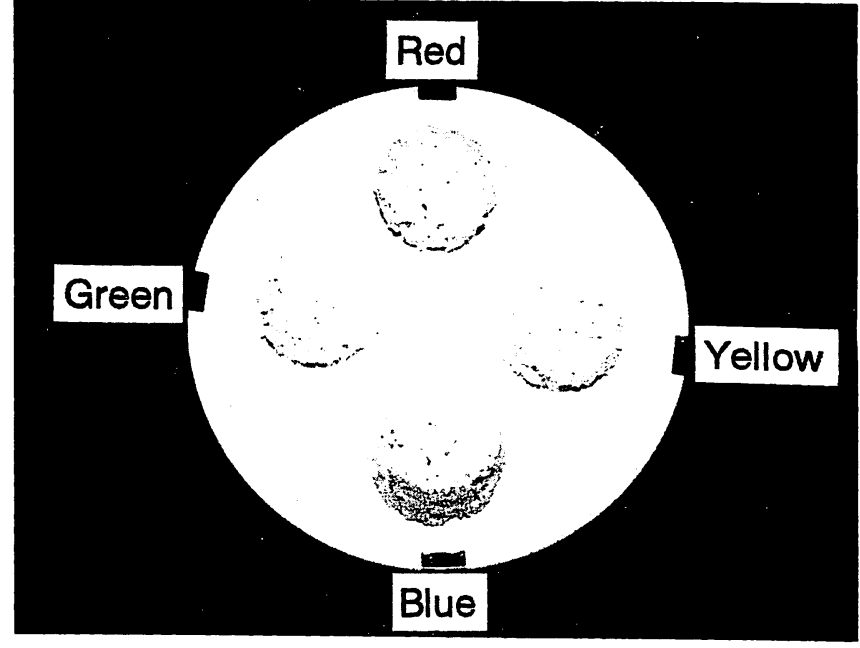

Figure 3-Cooked rice samples for sensory testing; one reference sample labeled red and three compared samples labeled yellow, blue, and green on a plate.

windows. Panelists evaluated rice samples under the lights during the test.

The sensory test was a multiple comparisons test. At the test a reference sample was labeled with a red color tape and presented to panelists with three compared samples labeled with yellow, blue, and green color tapes on a white $23.5 \mathrm{~cm}$ diameter plate (fig. 3). The amount of one cooked rice sample presented was about $40 . \mathrm{g}$, which was enough quantity for a panelist to decide his/her evaluation. The reference sample was always 'Nipponbare' variety grown in Shiga prefecture in Japan in each test. The order of the three compared samples on the plate was balanced by an experimental design (Latin squares method) for each panel group. Panelists continually received two plates in each test and were asked to compare three samples with the reference sample on the basis of five sensory determinations, i.e., appearance, aroma, hardness, cohesiveness, and overall flavor of cooked rice. The directions of difference between the reference sample and three compared samples in the overall flavor, for instance, were "good" and "bad", and the degrees of difference were "no difference", "very slight difference", "slight difference", "moderate difference", "much difference" and "extreme difference". Numerical scores were assigned to the directions and degrees with "extremely better than the reference" equaling +5 , "no difference to the reference" equaling zero and "extremely worse than the reference" equaling -5 . The reference sample was always scored zero. The evaluation value ranged within \pm 5 for appearance, aroma and overall flavor, and \pm 3 for the other items on a discrete scale.

The overall flavor was called the reference rice taste evaluation.

\section{VISIBLE AND NEAR-INFRARED SPECTROSCOPY}

Spectra of the rice samples were recorded with a visible and near-infrared spectrometer (model NIRS-6500, NIR Systems, Silver Spring, Md.). A spinning cup was used for all sample types, i.e., ground brown rice, whole grain brown rice, ground milled rice, and whole grain milled rice, from 
each sample (fig. 1). Grinding (20 g per each brown rice and white rice) was accomplished with a laboratory cyclone grinder (Udy, Fort Collins, Colo.) equipped with a $0.5 \mathrm{~mm}$ screen. Reflectance $(R)$ readings at $2 \mathrm{~nm}$ increments were collected over the visible and near-infrared wavelength range of 400 to $2500 \mathrm{~nm}$, and transformed to $\log _{10}(1 / \mathrm{R})$, giving 1050 data points per spectrum.

Before calibration and validation, the samples were randomly divided into two groups. The calibration set had 31 samples, and the validation set had 30 samples. Two calibration modeling methods, multiple linear regression (MLR) with forward selection method and partial least squares (PLS), were applied to the original spectra and their second derivative spectra (fig. 1). Gap and segment size for the second derivative spectra were $10 \mathrm{~nm}$ and $20 \mathrm{~nm}$ respectively. Spectra data processing and calibration modeling methods were summarized in William (1987) and Martens et al. (1987). Near-infrared spectral analysis software (NSAS, NIR Systems, Silver Spring, Md.) was used to process the data and make the calibration models.

\section{RESULTS AND DisCUSSION}

\section{Physicochemical Properties and Sensory \\ Evaluation}

The mean, maximum, minimum, and standard deviation (SD) of physicochemical properties and sensory evaluation for 61 rice samples are shown in table 1 .

The sensory scores evaluated by each panelist sometimes varied within \pm 5 or \pm 3 for each determination, and the scores were averaged to form each determination value per sample. The average score of each sample varied accordingly within almost \pm 1 for each determination as shown in table 1 . Because the rice sample set in this study was collected from Japanese short-grain varieties, the range of each physicochemical property and sensory evaluation was smaller than if the study had included medium-grain and long-grain varieties. But they were presented to show typical values of commercial short-grain rice grown in Japan.

Table 1. Physicochemical properties and sensory evaluation of 61 rice samples

\begin{tabular}{lccccc}
\hline Items & Unit & Mean & Max. & Min. & SD \\
\hline Moisture content & $(\%)$ & 15.7 & 17.2 & 14.0 & 0.7 \\
Amylose content & $(\%)$ & 19.0 & 22.7 & 14.8 & 1.6 \\
Protein content & $(\%)$ & 7.0 & 8.7 & 5.8 & 0.6 \\
Free fat acidity & $(\mathrm{mg})$ & 9.2 & 24.1 & 2.7 & 3.6 \\
\hline Whiteness & $(-)$ & 34.5 & 37.5 & 30.8 & 1.4 \\
Saturation & $(-)$ & 8.6 & 9.6 & 7.7 & 0.5 \\
Translucency & $(-)$ & 88.6 & 106.0 & 60.0 & 9.1 \\
\hline Texturogram A1 & $(\mathrm{TU})$ & 14.6 & 17.6 & 11.4 & 1.2 \\
Amylogram MV & $(\mathrm{BU})$ & 627 & 852 & 399 & 105 \\
RVA Peak & $(\mathrm{RVU})$ & 503 & 615 & 427 & 41 \\
\hline Appearance & $(-)$ & 0.00 & 0.62 & -1.00 & 0.41 \\
Aroma & $(-)$ & 0.02 & 0.58 & -0.69 & 0.26 \\
Hardness & $(-)$ & -0.18 & 0.57 & -1.03 & 0.31 \\
Cohesiveness & $(-)$ & 0.04 & 0.74 & -0.65 & 0.30 \\
Overall flavor & $(-)$ & -0.06 & 0.48 & -0.81 & 0.32 \\
\hline
\end{tabular}

(-):Non-dimension; (TU):Texturograph Unit; (BU):Brabender Unit; (RVU):Rapid Visco Unit.

\section{Correlation Coefficients Between \\ Physicochemical Properties and Sensory \\ Evaluation}

Correlation coefficients between physicochemical properties and sensory evaluation are shown in table 2 .

Amylose content had a significant correlation with hardness $(r=0.39)$ and cohesiveness $(r=-0.37)$. Protein content had a significant correlation with aroma $(r=-0.46)$, cohesiveness $(r=-0.28)$, and overall flavor $(r=-0.45)$. Free fat acidity had a significant correlation with appearance $(r=$ $-0.44)$ and overall flavor $(r=-0.47)$. This result indicated that these constituents significantly affected sensory evaluations.

Whiteness, saturation, and translucency were rice properties measured with visible light. Whiteness had a significant correlation with overall flavor $(r=0.29)$. Saturation and translucency had significant correlations with appearance $(r=-0.35$ and $r=0.54)$, aroma $(r=-0.37$ and $r$ $=0.29)$, and overall flavor $(r=-0.34$ and $r=0.35)$. This result suggested that the rice properties measured with visible light gave important information about rice taste.

Texturogram A1 had a significant correlation with hardness $(r=0.46)$ and cohesiveness $(r=-0.26)$. However, correlations between amylograph and rapid visco analyzer measurements of the viscosity of rice flour paste, and panelist's evaluations of the texture of cooked rice were very low.

Overall flavor had a highly significant correlation with the appearance $(r=0.72)$, aroma $(r=0.64)$, and cohesiveness $(r=0.62)$ of cooked rice. Cooked rice with a good appearance, nice aroma, and high cohesiveness appeared to get a high taste score. A multiple correlation analysis was made to find out the contribution of appearance, aroma and cohesiveness to overall flavor. The coefficient of determination $\left(r^{2}\right)$ was determined to be 0.70 , which meant that about $70 \%$ of overall flavor was determined by appearance, aroma, and cohesiveness.

Table 2. Correlation coefficients between physicochemical properties and sensory evaluation $(n=61)$

\begin{tabular}{|c|c|c|c|c|c|}
\hline & $\begin{array}{l}\text { Appear- } \\
\text { ance }\end{array}$ & Aroma & $\begin{array}{c}\text { Hard- } \\
\text { ness }\end{array}$ & $\begin{array}{l}\text { Cohesive- } \\
\text { ness }\end{array}$ & $\begin{array}{l}\text { Overall } \\
\text { Flavor }\end{array}$ \\
\hline Moisture content & 0.15 & 0.16 & -0.19 & 0.12 & 0.20 \\
\hline Amylose content & 0.03 & 0.13 & $0.39 * *$ & $-0.37 * *$ & 0.00 \\
\hline Protein content & -0.22 & $-0.46 * * *$ & 0.17 & $-0.28 *$ & $-0.45 * * *$ \\
\hline Free fat acidity & $-0.44 * * *$ & -0.23 & 0.11 & -0.15 & $-0.47 * * *$ \\
\hline Whiteness & 0.22 & 0.25 & 0.06 & 0.14 & $0.29 *$ \\
\hline Saturation & $-0.35 * *$ & $-0.37 * *$ & 0.03 & $-0.31 *$ & $-0.34 * *$ \\
\hline Translucency & $0.54 * * *$ & $0.29 *$ & 0.02 & 0.07 & $0.35 * *$ \\
\hline Texturogram Al & -0.10 & 0.13 & $0.46 * * *$ & * $-0.26 *$ & -0.22 \\
\hline Amylogram MV & -0.06 & -0.12 & -0.14 & -0.08 & 0.03 \\
\hline RVA Peak & -0.08 & -0.13 & -0.05 & -0.05 & -0.01 \\
\hline Appearance & $1.00^{r}$ & $0.55 * * *$ & $-0.26 *$ & $0.43 * * *$ & $0.72 * * *$ \\
\hline Aroma & & 1.00 & -0.14 & $0.33 * *$ & $0.64 * * *$ \\
\hline Hardness & & & 1.00 & $-0.41 * * *$ & $-0.33 * *$ \\
\hline Cohesiveness & & . & & 1.00 & $0.62 * * *$ \\
\hline Overall flavor & & & & & 1.00 \\
\hline
\end{tabular}

\section{Calibration and Validation for Rice \\ Taste Evaluation}

The results of calibration and validation for rice taste evaluation (overall flavor) are summarized in table 3 . 
Performances of the MLR models and PLS models were almost the same. Calibration models obtained from milled rice appeared to be better than those obtained from brown rice. Calibration models obtained from whole grain milled rice appeared to be better than those obtained from ground milled rice because the sample in the sensory test was neither brown rice nor ground milled rice, and whole grain milled rice was the sample closest in style to cooked rice in the sensory test.

The selected wavelengths of the MLR models consisted of two wavelengths in the NIR region and one in the visible region. The NIR wavelengths were considered to be referred to protein and starch (Murray et al., 1987). These constituents had correlation to the texture of cooked rice, such as hardness and cohesiveness. The visible wavelengths for brown rice and milled rice were in the yellow range and in the blue range, respectively. These selected wavelengths in the visible region seemed to be affected by the color of brown rice and milled rice. This result proved that the role of information about constituents and appearance was very important in evaluating rice taste.

Figure 4 shows a correlation between reference taste value and VIS/NIR validation value. The calibration model used was the best performance one in this study, which was obtained from original spectra of whole grain milled rice using MLR. The correlation coefficient ( $r$ ) of the validation set was 0.62 and the standard error of prediction (SEP) was 0.27 . The correlation coefficient of 0.62 was much better than those reported for commercial rice-taste meters by Kawamura et al. (1996). However, this performance was not accurate enough to indicate that the estimated rice taste

Table 3. Calibration and validation for rice taste evaluation (overall flavor)

\begin{tabular}{|c|c|c|c|c|c|c|c|c|c|}
\hline \multirow{4}{*}{$\begin{array}{l}\text { Sample } \\
\text { Brown } \\
\text { rice }\end{array}$} & \multicolumn{5}{|c|}{ Calibration Model by MLR $(n=31)$} & \multicolumn{4}{|c|}{ Validation $(n=30)$} \\
\hline & \multirow{3}{*}{$\begin{array}{l}\text { Style } \\
\text { Ground }\end{array}$} & \multirow{2}{*}{$\frac{\text { Spectra }}{\text { 2nd deriv. }}$} & \multicolumn{3}{|c|}{$\begin{array}{l}\text { Wavelength } \\
\text { (1st, 2nd, 3rd) }\end{array}$} & \multirow{2}{*}{$\begin{array}{c}\text { Bias } \\
-0.10\end{array}$} & \multirow{2}{*}{$\begin{array}{l}\text { SEP } \\
0.30\end{array}$} & \multirow{2}{*}{$\frac{r}{0.46 *}$} & \multirow{2}{*}{$\frac{\mathrm{r}^{2}}{0.21}$} \\
\hline & & & 1650 & 2090 & 574 & & & & \\
\hline & & Original & 16502 & 2090 & 572 & -0.11 & 0.34 & 0.27 & 0.07 \\
\hline & Whole & 2nd deriv. & 1650 & 2090 & 576 & -0.12 & 0.34 & 0.25 & 0.06 \\
\hline & grain & Original & 16502 & 2090 & 576 & -0.12 & 0.33 & 0.32 & 0.10 \\
\hline Milled & Ground & 2nd deriv. & 2094 & 2180 & 440 & -0.06 & 0.30 & $0.45 *$ & 0.20 \\
\hline \multirow[t]{4}{*}{ rice } & & Original & 21002 & 2180 & 426 & -0.09 & 0.28 & $0.56 * *$ & 0.31 \\
\hline & Whole & 2nd deriv. & 20222 & 2200 & 442 & -0.09 & 0.30 & $0.46 *$ & 0.21 \\
\hline & grain & Original & 20222 & 2200 & 450 & -0.11 & 0.27 & $0.62 * * *$ & 0.38 \\
\hline & \multicolumn{3}{|c|}{$\begin{array}{l}\text { Calibration Model by PLS } \\
(\mathrm{n}=31)\end{array}$} & \multicolumn{6}{|c|}{ Validation $(n=30)$} \\
\hline Sample & Style & Spectra & $\begin{array}{l}\text { No. of } \\
\text { Factors }\end{array}$ & Bia & & SEP & & $\mathbf{r}$ & $\mathbf{r}^{2}$ \\
\hline Brown & Ground & 2nd deriv. & 3 & -0.0 & & 0.30 & & $0.45 *$ & 0.20 \\
\hline \multirow[t]{3}{*}{ rice } & & Original & 1 & -0.0 & & 0.36 & & 0.07 & 0.01 \\
\hline & Whole & 2nd deriv. & 1 & -0.0 & & 0.34 & & 0.14 & 0.02 \\
\hline & grain & Original & 1 & -0.1 & & 0.32 & & 0.34 & 0.12 \\
\hline Milled & Ground & 2nd deriv. & 2 & -0.0 & & 0.30 & & $0.47^{* *}$ & 0.22 \\
\hline \multirow[t]{3}{*}{ rice } & & Original & 1 & -0.0 & & 0.35 & & 0.06 & 0.00 \\
\hline & Whole & 2nd deriv. & 1 & -0.1 & & 0.30 & & $0.48 * *$ & 0.23 \\
\hline & grain & Original & 2 & -0.1 & & 0.28 & & $0.55 * *$ & 0.31 \\
\hline
\end{tabular}

$* * *, * *$ and $*$ indicate that this correlation coefficient is statistically significant at $0.1 \%, 1 \%, 5 \%$, respectively.

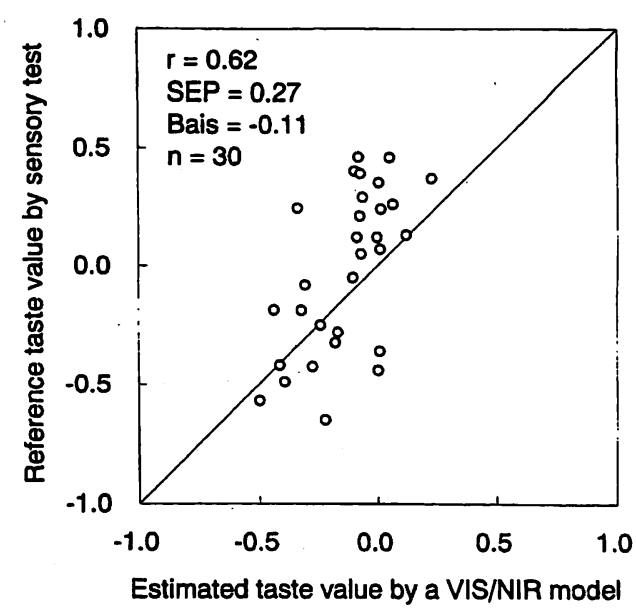

Figure 4-Correlation between reference taste value and VIS/NIR validation value.

value by the calibration model should be used in place of the sensory test.

Using the VIS/NIR spectra and the best calibration model in this study to classify rice samples into two qualitative groups or three qualitative groups gave a probability for classifying them correctly of $71 \%$ and $54 \%$, respectively (Shenk et al., 1993). It would therefore appear that VIS/NIR technology could be used for classifying rice samples into qualitative groups from poor taste to the best taste.

If VIS/NIR technology could be used to determine aroma, the probability of determining taste would be then much higher. But the aroma information was very difficult to detect since constituent content responsible for aroma was only a few parts per million.

\section{CONCLUSIONS}

This study resulted in five conclusions:

Some physicochemical properties, such as protein content, free fat acidity, saturation; and translucency significantly affected overall flavor.

The better the appearance and aroma, and the higher the cohesiveness of cooked rice was, the higher the taste evaluation.

Calibration models obtained from whole grain milled rice had higher performance than the others.

The information about constituents and appearance was very important in evaluating rice taste using VIS/NIR technology.

VIS/NIR technology could be used for classifying rice samples into qualitative groups, such as poor taste, better taste and the best taste.

\section{REFERENCES}

Delwiche, S. R., M. M. Bean, R. E. Miller, B. D. Webb and P. C. Williams. 1995. Apparent amylose content of milled rice by near-infrared reflectance. Cereal Chem. 72(2):182-187.

Delwiche, S. R., K. S. McKenzie and B. D. Webb. 1996. Quality characteristics in rice by near-infrared reflectance analysis of whole-grain milled samples. Cereal Chem. 73(2):257-263. 
Inatsu, O. 1988. Studies on improving the eating quality of Hokkaido rice. Report of Hokkaido Prefectural Agric. Experiment Stations 66:3-7.

Iwamoto, M., T. Suzuki, N. Kongseree, J. Uozumi and O. Inatsu. 1986. Analysis of protein and amino acid contents in rice flour by near-infrared spectroscopy. Nippon Shokuhin Kogyo Gakkaishi 33(12):848-853.

Kawamura, S., M. Natsuga, S. Kouno and K. Itoh. 1996. Instrument analysis and sensory test for rice taste evaluation. $J$. Japanese Soc. Agric. Eng. 58(4):95-100.

Martens, H. and T. Naes. 1987. Multivariate calibration by data compression. In Near-Infrared Technology in the Agricultural and Food Industries, eds. P. Williams and K. Norris, ch. 4:5787. St. Paul, Minn.: Am. Assoc. Cereal Chemists, Inc.

Murray, I. and P. C. Williams. 1987. Chemical principles of nearinfrared technology. In Near-Infrared Technology in the Agricultural and Food Industries, eds. P. Williams and K. Norris, ch. 2:17-34. St. Paul, Minn.: Am. Assoc. Cereal Chemists, Inc.

Natsuga, M., S. Kawamura and K. Itoh. 1993. Accuracy of nearinfrared reflectance spectroscopy in determining constituent content of grain. J. Japanese Soc. Agric. Eng. 55(1):109-115.
Shenk, J. S. and M. O. Westerhaus. 1993. Analysis of Agriculture and Food Products by Near Infrared Reflectance Spectroscopy, 13-16. Port Matilda, $\mathrm{Pa}$.: Infrasoft International Co.

Villareal, C. P., N. M. Cruz and B. O. Juliano. 1994. Rice amylose analysis by near-infrared transmittance spectroscopy. Cereal Chem. 71(3):292-296.

William, R. H. 1987. Data analysis: Wavelength selection methods. In Near-Infrared Technology in the Agricultural and Food Industries, eds. P. Williams and K. Norris, ch. 3:35-55. St. Paul, Minn.: Am. Assoc. Cereal Chemists, Inc.

Williams, V. R., W. T. Wu, H. Y. Tsai and H. G. Bates. 1958. Varietal differences in amylose content of rice starch. J. Agric. and Food Chem. 6(1):47-48. 